\title{
PENGARUH TERAPI ACTIVE CYCLE OF BREATHING TECHNIQUE (ACBT) TERHADAP FREKUENSI PERNAFASAN (RESPIRATORY RATE) PADA PENDERITA TUBERKULOSIS PARU DI RUMAH SAKIT UMUM IMELDA PEKERJA INDONESIA MEDAN
}

\author{
Eka Nugraha Varida Naibaho, Sri Mega Herlina Kabeakan \\ Program Studi Sarjana Keperawatan, Universitas Imelda Medan \\ Email: Naibahoekanugraha@yahoo.com; Srymegakabeakan98@gmail.com
}

\begin{abstract}
Pulmonary tuberculosis is a major public health problem in the world and is the second leading cause of death from infectious diseases. The purpose of this study was to determine the effect of active cycle of breathing technique (ACBT) therapy on breathing frequency in patients with pulmonary tuberculosis. Quantitative research method, with a Quasi Experimental research design with a pre-test and one-group post-test approach. The study was carried out in the Orchid room of the Imelda Indonesian Workers General Hospital in Medan in July - August 2021. The study population was 45 patients with pulmonary tuberculosis and the sample technique of this study was Nonprobability Sampling. The number of samples was 41 pulmonary tuberculosis patients according to the researcher's criteria. The data analysis technique used is Wilcoxon test analysis. The results of the study There was an effect of breathing patterns before the administration of active cycle of breathing technique (ACBT) Therapy on the improvement of respiratory frequency in patients with pulmonary tuberculosis with a value of $\mathrm{M} \pm \mathrm{SD}=17.1081 \pm 2.94188$. There is an effect of breathing pattern after administration of active cycle of breathing technique (ACBT) Therapy on the respiratory frequency of Pulmonary Tuberculosis Patients with a value of $\mathrm{M} \pm \mathrm{SD}=$ $27.0400 \pm 2.82076$. There is a difference in the effect of breathing patterns before and after administration of active cycle of breathing technique (ACBT) therapy on the Improvement of respiratory frequency in pulmonary tuberculosis patients with a significant value of $0.000<0.005$.

Keywords: Pulmonary Tuberculosis, Active Cycle of Breathing Technique, Respiratory Rate.
\end{abstract}

\begin{abstract}
Abstrak
Tuberkulosis paru adalah masalah pokok kesehatan pada masyarakat didunia dan merupakan penyebab kematian ke dua dari penyakit infeksi. Tujuan penelitian untuk mengetahui pengaruh pemberian terapi active cycle of breathing technique (ACBT) terhadap frekuensi pernafasan pada penderita tuberkulosis paru. Metode penelitian kuantitatif, dengan desain penelitian Quasi Eksperiment dengan pendekatan pre test dan post test one group. Penelitian dilaksanakan di ruangan Anggrek Rumah Sakit Umum Imelda Pekerja Indonesia Medan pada bulan Juli - Agustus 2021. Populasi penelitian sebanyak 45 orang pasien Tuberkulosis Paru dan teknik sampel penelitin ini adalah Nonprobability Sampling. Jumlah sampel 41 orang pasien tuberkulosis paru sesuai dengan kriteria peneliti. Teknik analisa data yang digunakan adalah analisis uji Wilcoxon. Hasil penelitian ada pengaruh pola nafas sebelum pemberian terapi active cycle of breathing technique (ACBT) terhadap perbaikan frekuensi pernafasan pada penderita tuberkulosis paru dengan nilai $\mathrm{M}$ $\pm \mathrm{SD}=17.1081 \pm 2.94188$. Ada pengaruh pola nafas sesudah pemberian terapi active cycle of breathing technique (ACBT) terhadap frekuensi pernafasan pasien tuberkulosis paru dengan nilai $\mathrm{M} \pm \mathrm{SD}=27.0400 \pm 2.82076$. Ada perbedaan pengaruh pola nafas sebelum dan sesudah pemberian terapi active cycle of breathing technique (ACBT) terhadap perbaikan frekuensi pernafasan pasien tuberkulosis paru dengan nilai signifikan $0,000<0,005$.
\end{abstract}

Kata Kunci: Tuberkulosis Paru, Active Cycle of Breathing Technique, Frekuensi Pernafasan. 


\section{PENDAHULUAN}

Tuberkulosis paru adalah masalah pokok kesehatan pada masyarakat di dunia, dimana masalah ini masih menjadi perhatian dunia. Menurut Global Tuberculosis Report 2017 yang disusun oleh World Health Organization (WHO) menjelaskan bahwa Tuberkulosis paru masih terpilih jadi satu dari sepuluh penyebab kematian di seluruh dunia, hingga saat ini belum ada satu negara pun yang bebas TB Paru, namun setiap negara berbeda angka insidensinya [1]. Setiap tahun di dunia diperkirakan terdapat 8,7 juta kasus baru tuberkulosis dan 1,7 juta kematian karena TB Paru. Bila tidak diupayakan pengendalian yang memadai 25 tahun kemudian diperkirakan angka kematian akan mencapai 40 juta orang per tahun [2].

Secara global, pada tahun 2018 terdapat 11,1 juta kasus insiden TB paru yang setara dengan 130 kasus per 100.000 penduduk. Lima negara dengan insiden kasus tertinggi yaitu India, China, Indonesia, Philipina, dan Pakistan. Data berdasarkan usia diperkirakan sebanyak $57 \%$ kasus paling banyak terinfeksi TB paru yaitu pria yang berusia lebih dari 15 tahun, wanita $32 \%$ dan anak-anak yang berusia kurang dari 15 tahun dengan persentase sebanyak $11 \%$. Delapan Negara yang menjadi peringkat pertama untuk kejadian TB paru adalah India sebanyak $27 \%$, Cina sebanyak 9\%, Indonesia sebanyak $8 \%$, Filipina sebanyak $6 \%$, Pakistan sebanyak 5\%, Nigeria sebanyak 4\%, Bangladesh sebanyak 4\% dan Afrika Selatan sebanyak 3\% [3].

Tingginya kasus tuberkulosis perlu ditangani secara tepat karena infeksi tuberkulosis tidak hanya menyerang paruparu dan saluran pernafasan. Penyakit Tuberkulosis memiliki beberapa tanda dan gejala yang terdiri dari sesak nafas, batuk darah, dahak bercampur darah, demam, badan lemas, nafsu makan menurun, berat badan menurun, malaise, berkeringat malam hari tanpa kegiatan fisik, demam meriang lebih dari satu bulan. Beberapa tanda dan gejala yang sering ditemukan salah satunya sangat memperburuk kondisi pasien yaitu sesak nafas [4].
Gangguan pola nafas jika tidak di tangani akan mengakibatkan komplikasi yang memperburuk kondisi pasien. Untuk mengobati sesak nafas, intervensi keperawatan mandiri yang dapat dilakukan salah satunya pemberian teknik Active Cycle Of Breathing (ACBT). Latihan teknik pernapasan siklus aktif atau active cycle of breathing technique merupakan salah satu latihan pernapasan untuk mengontrol pernapasan agar menghasilkan pola pernapasan yang tenang dan ritmis sehingga menjaga kinerja otot-otot pernapasan dan merangsang keluarnya sputum untuk membuka jalan napas [5].

Menurut Arifin, S (2019) bahwa pemberian Active Cycle of Breathing Technique (ACBT) ialah latihan pernapasan dengan teknik Active Cycle Of Breathing Technique (ACBT) terbukti mampu mengatasi permasalahan terkait pembersihan jalan napas sehingga didapati hasil peningkatan dalam kapasitas fungsional pernapasan yaitu pengurangan sesak napas dan pengurangan retensi sputum pada jala napas dengan parameter pengukuran menggunakan borg scale.

Berdasarkan data survey awal di Rumah Sakit Umum Imelda Pekerja Indonesia Medan mulai dari bulan JanuariJuni 2021, jumlah penderita Tuberkulosis Paru sebanyak 137 orang yang terdiri dari Laki-laki 82 orang dan Perempuan 55 orang. Hasil wawancara dengan pasien Tuberkulosis Paru yang mengalami gangguan pola nafas di Rumah Sakit Umum Imelda Pekerja Indonesia, bahwa pasien sering mengeluh sesak nafas, sulit tidur, batuk/batuk berdarah. Dari latar belakang diatas, peneliti ingin mengetahui apakah ada Pengaruh Pemberian Terapi Active Cycle Of Breathing (ACBT) Terhadap Peningkatan Pola Nafas Pada Penderita Tuberkulosis Paru Di Rumah Sakit Umum Imelda Pekerja Indonesia Medan.

\section{METODE PENELITIAN}

Jenis penelitian yang digunakan adalah jenis penelitian kuantitatif, dengan desain penelitian yang digunakan adalah Quasi Eksperiment dengan pendekatan pre 
test dan post test one group yaitu melakukan perbandingan antar kelompok sebelum dan sesudah diberikan perlakuan dengan one group

Pada penelitian ini responden diberikan intervensi yaitu terapi Active Cycle Of Breathing Technique (ACBT) kepada pasien Tuberkulosis Paru yang mengalami gangguan pola nafas di Rumah Sakit Umum Imelda Pekerja Indonesia Medan.

Gambar 3.1 Rancangan one group pre test - post test

\begin{tabular}{|c|c|}
\hline $\begin{array}{r}\text { Pre } \\
\text { test } \\
\text { O1 }\end{array}$ & $\begin{array}{c}\text { Intervensi } \\
\mathrm{X}_{1}, \mathrm{X}_{2}, \mathrm{X}_{3}, \mathrm{X}_{4}, \mathrm{X}_{5}\end{array}$ \\
\hline O1: & $\begin{array}{l}\text { Pre test (sebelum di berikan terapi } \\
\text { Active Cycle Of Breathing } \\
\text { Technique (ACBT) }\end{array}$ \\
\hline X: & $\begin{array}{l}\text { Intervensi dilakukan pemberian } \\
\text { terapi Active Cycle Of Breathing } \\
\text { Technique (ACBT) dalam } \\
\text { membantu perbaikan pola } \\
\text { nafas pada pasien Tuberkulosis } \\
\text { Paru sebanyak } 5 \text { kali dalam } \\
\text { seminggu (4 kali/4 siklus dalam } 1 \\
\text { hari). }\end{array}$ \\
\hline $\mathrm{O} 2:$ & $\begin{array}{l}\text { Post test (sesudah diberikan terapi } \\
\text { Active Cycle of Breathing } \\
\text { Technique (ACBT). }\end{array}$ \\
\hline
\end{tabular}

Penelitian ini dilaksanakan di ruangan Anggrek Rumah Sakit Umum Imelda Pekerja Indonesia Medan. Waktu penelitian ini mulai dilakukan dari awal penyusunan proposal sampai penyusunan hasil yaitu pada bulan Juli-Agustus 2021 . Populasi dalam penelitian ini adalah 45 orang pasien yang mengalami Tuberkulosis Paru di Rumah Sakit Umum Imelda Pekerja Indonesia Medan di Ruangan Anggrek. Teknik sampling merupakan teknik pengambilan sampel. Teknik pengambilan sampel dalam penelitin ini adalah Nonprobability Sampling, Sampel dalam penelitian ini adalah pasien yang mengalami Tuberkulosis Paru sebanyak 41 responden yang memenuhi syarat dalam penelitian.

\section{Tahap Persiapan}

Tahap awal yang harus dilakukan adalah melakukan persiapan untuk kelancaran pelaksanaan penelitian, berupa surat izin penelitian dari institusi pendidikan yaitu program studi S1 keperawatan Universitas Imelda Medan, pengumpulan data dilakukan setelah mendapat surat permohonan izin yang diperoleh dari Rumah Sakit Umum Imelda Pekerja Indonesia.

Tahap selanjutnya peneliti kemudian ke ruangan responden serta menjelaskan tentang penelitian yang akan dilaksanakan, peneliti meminta kesedian responden untuk berpartisipasi dalam penelitian. Apabila calon responden bersedia, maka calon responden diminta untuk menandatangani informed consent.

\section{Tahap Pelaksanaan}

Tahap pelaksana peneliti menentukan responden sesuai dengan kriteria inklusi yang telah ditetapkan sebelumnya. Selanjutnya peneliti melakukan kontrak waktu dengan responden. Tahap pelaksanaan peneltian terdiri atas :

1. Pre test

Setelah peneliti menjelaskan tujuan penelitian dan sudah kontrak waktu dengan responden, kemudian peneliti memberikan tindakan teknik Teknik Active Cycle of Breathing (ACBT) terhadap kelompok yang akan diberikan intervensi. Sebelum melakukan intervensi tersebut, peneliti terlebih dahulu menjelaskan tujuan dan prosedur pelaksanaan pemberian teknik Teknik Active Cycle Of Breathing (ACBT) tersebut. Hasil pengukuran didokumentasikan dalam lembar tabulasi data.

2. Intervensi

Hari pertama peneliti melakukan pengukuran frekuensi pernapasan terhadap kelompok intervensi. Setelah diukur di tulis hasilnya, peneliti kemudian melakukan atau menganjurkan terapi Active Cycle of Breathing Technique (ACBT) kepada pasien. Setelah 1 siklus intervensi Active Cycle Of Breathing Technique (ACBT) dilakukan dan berhasil pada siklus 1 dan di 
evaluasi frekuensi pernafasan di siklus 1 . Jika siklus 1 gagal peneliti mengulang kembali intervensi kepada pasien pada siklus 1. Setelah berhasil, dilanjutkan siklus ke 2, siklus ke 3, dan siklus ke 4. Jika siklus ke 2, siklus ke 3 dan siklus ke 4 gagal, peneliti mengulang kembali siklus yang gagal kepada responden. setelah seluruhnya berhasil maka peneliti melakukan evaluasi akhir. Setiap responden diberikan intervensi Teknik Active Cycle Of Breathing (ACBT) satu kali dalam satu hari sebanyak 4 siklus selama 5 hari.

3. Post test

Pengukuran frekuensi pernapasan dilakukan secara time series yaitu mengukur variabel dependen setiap hari setelah diberikan perlakuan selama 5 hari. Pengukuran pernapasan menggunakan jam tangan dan di dokumentasikan dalam lembar tabulasi data. Setelah dilakukan 4 siklus, pasien langsung di evaluasi.

\section{Teknik Analisa Data \\ Univariat}

Analisa univariat dilakukan untuk menjabarkan secara deskriptif melalui distribusi frekuensi dan data masing-masing variabel. Kategori data yang meliputi jenis kelamin, usia, pendidikan, lama merokok dan berapa lama menderita Tuberkulosis Paru.

\section{Bivariat}

Analisa data bivariat digunakan untuk membuktikan adanya hubungan yang signifikan antara variabel independen dan variabel dependen digunakan analisis uji Wilcoxon. Uji Wilcoxon adalah menilai pengaruh variabel pemberian teknik ACBT terhadap perbaikan pola nafas. Analisis ini dilakukan untuk mengetahui pengaruh terapi Active Cycle of Breathing Technique (ACBT) pada pasien Tuberkulosis Paru di Rumah Sakit Umum Imelda Pekerja Indonesia Medan. Hasil uji menunjukkan bahwa variabel tersebut berdistribusi normal dimana nilai $\mathrm{p}<0,05$.

\section{HASIL PENELITIAN \\ Analisa Univariat}

Tabel 1 Distribusi Frekuensi Karakteristik Data Demografi Pasien Tuberkulosis Paru

\begin{tabular}{|c|c|c|}
\hline \multirow[t]{2}{*}{ Karakteristik } & \multicolumn{2}{|c|}{ Responden } \\
\hline & $\mathbf{F}$ & $\%$ \\
\hline \multicolumn{3}{|l|}{ Usia } \\
\hline $35-40$ & 5 & 12,2 \\
\hline $45-50$ & 8 & 19,5 \\
\hline $51-55$ & 12 & 29,3 \\
\hline$>65$ & 16 & 39,0 \\
\hline Total & 41 & 100 \\
\hline \multicolumn{3}{|l|}{ Jenis Kelamin } \\
\hline Laki-laki & 25 & 61,0 \\
\hline Perempuan & 16 & 39,0 \\
\hline Total & 41 & 100 \\
\hline \multicolumn{3}{|l|}{ Pendidikan } \\
\hline SD & 22 & 53,7 \\
\hline SMP & 10 & 24,4 \\
\hline SMA & 6 & 14,6 \\
\hline PT & 3 & 7,3 \\
\hline \multicolumn{3}{|l|}{ Total } \\
\hline \multicolumn{3}{|l|}{ Pekerjaan } \\
\hline Buruh & 21 & 51,2 \\
\hline Wiraswasta & 9 & 22,0 \\
\hline PNS & 5 & 12,2 \\
\hline Lainnya & 6 & 14,6 \\
\hline Total & 41 & 100 \\
\hline
\end{tabular}

Tabel 2. Distribusi Frekuensi Pre Test Perbaikan Pola Nafas

\begin{tabular}{|c|c|c|}
\hline Data & $\mathbf{F}$ & $\%$ \\
\hline \multicolumn{3}{|l|}{ Hari 1} \\
\hline Efektif & 19 & 46,3 \\
\hline Tidak Efektif & 22 & 53,7 \\
\hline Total & 41 & 100 \\
\hline \multicolumn{3}{|l|}{ Hari 2} \\
\hline Efektif & 22 & 53,7 \\
\hline Tidak Efektif & 19 & 46,3 \\
\hline Total & 41 & 100 \\
\hline \multicolumn{3}{|l|}{ Hari 3} \\
\hline Efektif & 19 & 46,3 \\
\hline Tidak Efektif & 22 & 53,7 \\
\hline Total & 41 & 100 \\
\hline \multicolumn{3}{|l|}{ Hari 4} \\
\hline Efektif & 27 & 65,9 \\
\hline Tidak Efektif & 14 & 34,1 \\
\hline Total & 41 & 100 \\
\hline
\end{tabular}




\begin{tabular}{lll}
\hline $\begin{array}{l}\text { Hari 5 } \\
\text { Efektif } \\
\text { Tidak Efektif }\end{array}$ & 25 & 61,0 \\
\hline Total & 16 & 39,0 \\
\hline
\end{tabular}

Tabel 3. Distribusi Frekuensi Post Test Perbaikan Pola Nafas

\begin{tabular}{|c|c|c|}
\hline Data & $\mathbf{F}$ & $\%$ \\
\hline \multicolumn{3}{|l|}{ Hari 1} \\
\hline Efektif & 25 & 61,0 \\
\hline Tidak Efektif & 16 & 39,0 \\
\hline Total & 41 & 100 \\
\hline \multicolumn{3}{|l|}{ Hari 2} \\
\hline Efektif & 20 & 48,8 \\
\hline Tidak Efektif & 21 & 51,2 \\
\hline Total & 41 & 100 \\
\hline \multicolumn{3}{|l|}{ Hari 3} \\
\hline Efektif & 25 & 61,0 \\
\hline Tidak Efektif & 16 & 39,0 \\
\hline Total & 41 & 100 \\
\hline \multicolumn{3}{|l|}{ Hari 4} \\
\hline Efektif & 21 & 51,2 \\
\hline Tidak Efektif & 20 & 48,8 \\
\hline Total & 41 & 100 \\
\hline \multicolumn{3}{|l|}{ Hari 5} \\
\hline Efektif & 22 & 53,7 \\
\hline Tidak Efektif & 19 & 46,3 \\
\hline Total & 41 & 100 \\
\hline
\end{tabular}

Hasil Bivariat

Tabel 4. Pengaruh Pemberian Teknik Active Cycle of Breathing (ACBT) Terhadap Perbaikan Pola Nafas Pada Penderita Tuberkulosis Paru (Pre-Post) Di Rumah Sakit Umum Imelda Pekerja Indonesia Medan

\begin{tabular}{lcc}
\hline \multicolumn{1}{c}{ Variabel } & M & SD \\
\hline Pre & 17.1081 & 2.94188 \\
Post & 27.0400 & 2.82076 \\
\hline
\end{tabular}

Tabel 5. Uji Wilcoxon

\begin{tabular}{l|c}
\hline & $\begin{array}{c}\text { Perbaikan pola } \\
\text { nafas - ACBT }\end{array}$ \\
\hline $\mathrm{Z}$ & $-3.873^{\mathrm{a}}$ \\
Asymp. Sig. (2-tailed) & .000 \\
\hline
\end{tabular}
a. Based on positive ranks
b. Wilcoxon signed ranks

\section{PEMBAHASAN}

Usia

Berdasarkan hasil yang didapatkan oleh peneliti distribusi frekuensi data demografi responden pada kelompok usia mayoritas yang berusia >65 sebanyak 16 responden $(39,0 \%)$.

Berbeda dengan penelitian sebelumnya yaitu pada kelompok umur tertinggi adalah kelompok umur 15-24 tahun dan 45-54 tahun dengan jumlah 62 kasus $(20,3 \%)$ dan terendah adalah kelompok umur $<15$ tahun dengan jumlah 14 kasus $(4,6 \%)$ [6].

Penelitian yang dilakukan sebelumnya di dapatkan hasil bahwa responden yang menderita Tuberkulosis paru mayoritas berusia 45-54 dan 55-64 [7], sedangkan penelitian yang lainnya didapatkan hasil mayoritas usia responden yang menderita tuberkulosis paru di dapatkan hasil berdasarkan umur di Puskesmas Bahu Kecamatan Malalayang Manado dalam penelitian ini berkisar antara 19-55 tahun [8].

\section{Jenis Kelamin}

Berdasarkan hasil yang didapatkan oleh peneliti distribusi frekuensi data demografi responden kelompok jenis kelamin di dapatkan mayoritas yang berjenis kelamin laki-laki sebanyak 25 responden $(61,0 \%)$.

Sejalan dengan hasil penelitian sebelumnya berdasarkan jenis kelamin tertinggi adalah laki-laki dengan jumlah 181 kasus $(59,3 \%)$ dan terendah adalah perempuan dengan jumlah 124 kasus $(40,7 \%)$ [6], sedangkan hasil penelitian lainnya menunjukkan bahwa responden yang menderita Tuberkulosis paru didominasi oleh laki-laki sebanyak 35 orang $(71,43 \%)$ [7].

\section{Pendidikan}

Berdasarkan hasil yang didapatkan oleh peneliti distribusi frekuensi data demografi responden pada kelompok pendidikan mayoritas yang pendidikan SD sebanyak 22 responden $(53,7 \%)$.

Berbeda dengan hasil penelitian sebelumnya yaitu hasil penelitian menunjukkan bahwa responden yang 
menderita Tuberkulosis paru didominasi oleh pendidikan tamat SMA [7], sedangkan hasil penelitian lainnya di dapatkan hasil bahwa mayoritas yang menderita tuberkulosisi paru distribusi penderita Tuberkulosis paru menurut pendidikan terakhir menunjukkan bahwa terdapat $46,8 \%$ penderita yang berpendidikan SLTA dan perguruan tinggi selebihnya pendidikan SLTP dan SD, sehingga mayoritas penderita Tuberkulosis paru hasil penelitian ini mempunyai tingkat pendidikan menengah kebawah [9].

\section{Pekerjaan}

Berdasarkan hasil yang didapatkan oleh peneliti distribusi frekuensi data demografi responden pada kelompok pekerjaan mayoritas yang menderita Tuberkulosis Paru yaitu yang bekerja sebagai buruh sebanyak 21 responden $(51,2 \%)$.

Berbeda dengan hasil penelitian sebelumnya berdasarkan pekerjaan tertinggi adalah wiraswasta dengan jumlah 105 kasus $(34,4 \%)$ dan terendah adalah tukang/buruh dengan jumlah 2 kasus $(0,7 \%)$ [6], sedangkan hasil penelitian lainnya di dapatkan bahwa mayoritas yang menderita tuberkulosisi paru distribusi penderita Tuberkulosis paru menurut pekerjaan menunjukkan bahwa distribusi pekerjaan dari total 54 responden penderita Tuberkulosis paru mayoritas tidak memiliki pekerjaan tetap yaitu sebesar 39 orang $(72,2 \%)$ [9].

\section{Pengaruh Terapi Active Cycle Of Breathing Technique (ACBT), Frekuensi Respiratory Rate (RR).}

Berdasarkan hasil penelitian didapatkan hasil bahwa ada pengaruh pemberian terapi Active Cycle Of Breathing Technique (ACBT), frekuensi respiratory rate pada penderita tuberkulosis paru dengan nilai signifikan (2-tailed) $0,000<0,05$. Maka secara statistik ada pengaruh yang signifikan sebelum dan sesudah dilakukannya intervensi terapi Active Cycle Of Breathing Technique (ACBT), frekuensi respiratory rate pada penderita tuberkulosis paru di Rumah Sakit Umum Imelda Pekerja Indonesia Medan.
Hasil penelitian ini didukung oleh peneliti sebelumnya yang menyatakan bahwa teknik Active Cycel of Breathing menunjukkan perbedaan frekuensi pernapasan sebelum dan sesudah diberikan kombinasi fisioterapi dada dan Active Cycle Breathing Technique pada kelompok intervensi dan kelompok control [10]. Pada kelompok intervensi terdapat perbedaan yang signifikan frekuensi pernapasan sebelum dan sesudah diberikan intervensi dengan nilai $\mathrm{p}=$ $0,001(\mathrm{p}<0,05)$ dan pada kelompok kontrol juga terdapat perbedaan frekuensi pernapasan yang signifikan dengan nilai $\mathrm{p}=0,001(\mathrm{p}<$ $0,05)$.

Sedangkan menurut hasil penelitian lainnya yang menyatakan bahwa latihan pernapasan dengan teknik Active Cycle of Breathing (ACBT) terbukti dapat mengurangi sesak secara signifikan dilihat dari penurunan borg scale [11]. Latihan ini juga dapat digunakan pada saat terjadi serangan sesak sehingga dapat meringankan sesak yang dialami oleh pasien.

Hal ini juga sejalan dengan hasil penelitian sebelumnya yang menyatakan bahwa bahwa teknik permafasana Active Cycle Of Breathing (ACBT) mampu menurunkan respiratory rate (RR) karena terjadi peningkatan elastisitas dan compliance paru yang pada akhirnya meningkatkan ventilasi paru, dimana pengeluaran $\mathrm{CO}_{2}$ dan pemasukan $\mathrm{O}_{2}$ meningkat. Penurunan keluhan sesak penderita tubeberkulosis lebih cepat dicapai dengan latihan nafas Active Cycle of Breathing (ACBT) [12]. Hal ini karena terjadi pengeluaran mukus dari saluran pernafasan serta peninglkatan pemasukan $\mathrm{O}_{2}$

Hasil penelitian yang dilakukan oleh peneliti kepada responden yang mengalami Tuberkulosis paru dengan sesak nafas dengan rata-rata frekuensi pernafasan $>20 \mathrm{x} /$ menit. Setelah diberikan tindakan Teknik Active Cycle Of Breathing (ACBT), pasien yang mengalamisesak nafas sudah merasakan perubahan secara bertahap hingga intervensi yang diberikan selama 5 hari berturut-turut, hasil yang di dapatkan bahwa pasien 
memiliki rata-rata frekuensi pernafasan 1220x/menit.

Teknik Active Cycle of Breathing Technique (ACBT) adalah salah satu terapi nonfarmakologi yang bertujuan untuk membersihkan jalan nafas dari sputum yang merupakan produk dari infeksi atau proses patologi penyakit tersebut yang harus dikeluarkan dari jalan nafas untuk mengurangi sesak nafas, mengurangi batuk, perbaikan pola nafas, serta meningkatkan mobilisasi dinding dada [13].

Teknik terapi Active Cycle of Breathing Technique (ACBT) ini bisa dilakukan untuk dijadikan pola hidup pasien, untuk mengurangi akumulasi sputum dalam saluran pernapasan, mengurangi sesak nafas dan meningkatkan mobilisasi sangkar toraks sehingga kebutuhan oksigennya terpenuhi.

\section{KESIMPULAN}

1. Ada pengaruh pola nafas sebelum pemberian terapi Active Cycle of Breathing Technique (ACBT) terhadap frekuensi pernafasan (respiratory rate) pada penderita tuberkulosis paru denagan nilai $\mathrm{M} \pm \mathrm{SD}=17.1081 \pm 2.94188$.

2. Ada pengaruh pola nafas sesudah pemberian Teknik terapi Active Cycle Of Breathing Technique (ACBT terhadap frekuensi pernafasan (respiratory rate) pada penderita tuberkulosis paru dengan nilai $\mathrm{M} \pm \mathrm{SD}=27.0400 \pm 2.82076$.

3. Ada pengaruh pola nafas sebelum dan sesudah pemberian Teknik terapi Active Cycle Of Breathing Technique (ACBT) terhadap frekuensi pernafasan (respiratory rate) pada penderita tuberkulosis paru dengan nilai signifikan $0,000<0,005$.

\section{SARAN}

Diharapkan untuk mempertimbang kan penggunaan terapi Active Cycle Of Breathing Technique (ACBT) untuk mengatasi masalah frekuensi pernafasan (respiratory rate) pada penderita tuberkulosis paru

\section{REFERENSI}

1. WHO. (2017). Global tuberculosis report 2017. Geneva : World Health Organization. 15-49.

2. Kementerian Kesehatan R.I. (2013). Laporan Riset Kesehatan Dasar (Riskesdas) 2013. Jakarta : Badan Penelitian dan Pengembangan Kesehatan Kementerian Kesehatan RI.

3. WHO. (2019). Global tuberculosis report 2019. Geneva : World Health Organization.

4. Misnadiarly. (2016). Penyakit infeksi TB paru dan ektsra paru: mengenal, mencegah menanggulangi TBC paru pada anak pada kehamilan. Jakarta: Pustaka Populer Obor.

5. Guyton \& Hall. (2010. Buku ajar fisiologi kedokteran. Edisi 11. Jakarta : EGC

6. Debora, Y. (2020). Karakteristik penderita tuberkulosis paru di Wilayah Kerja Puskesmas Sentosa Baru Kecamatan Medan Perjuangan Kota Medan Tahun 2017-2018.

7. Fitria, E., Ramadhan, R., \& Rosdiana, R. (2017). Karakteristik penderita tuberkulosis paru di Puskesmas Rujukan Mikroskopis Kabupaten Aceh Besar. SEL Jurnal Penelitian Kesehatan, 4(1), 13-20.

8. Bawihu, L. C. (2017). Hubungan pengetahuan penderita tuberkulosis paru dengan tingkat kepatuhan dalam program pengobatan tuberkulosis paru di Puskesmas Bahu Kecamatan Malalayang Manado. Pharmacon, 6(4).

9. Tinartayu, S., \& Riyanto, B. U. D. (2015). SF-36 sebagai instrumen penilai kualitas hidup penderita tuberkulosis (TB) paru. Mutiara Medika: Jurnal Kedokteran dan Kesehatan, 15(1), 7-14.

10. Pakpahan, R. E. (2019). Pengaruh kombinasi fisioterapi dada dan active cycle breathing tecnique terhadap saturasi oksigen, frekuensi pernapasan, kemampuan mengeluarkan sputum dan lama hari rawat pada pasien penyakit paru obstruktif kronik di ruang rawat inap RSUP H. Adam Malik Medan. 
11. Arifin, S. (2019). Penggunaan active cycle of breathing technique pada kasus bronkiektasis et causa post tuberkulosis paru Rs Paru Dr. M Goenawan Cisarua Bogor : Analisis Kasus Berbasis Bukti. In Seminar Nasional Teknologi Terapan Berbasis Kearifan Lokal (Vol. 2, No. 1).

12. Suryati, I., \& SY, D. P. I. P. (2018). Perbedaan active cycle of breathing technique dan pursed lips breathing technique terhadap frekuensi nafas nafas pasien paru obstruksi kronik. In Prosiding Seminar Kesehatan Perintis E-ISSN (Vol. 2622, p. 2256).

13. Lestari, R. I. (2015). Manfaat active cycle of breathing technique (ACBT) bagi penderita penyakit paru obstruktif kronik (PPOK). Doctoral dissertation, Universitas Muhammadiyah Surakarta. 